\title{
II National Spanish Symposium on Horticultural Engineering
}

\author{
A. Ruiz-Canales ${ }^{1} \cdot$ M. Ferrández-Villena ${ }^{1}$
}

Published online: 23 October 2017

(C) Springer Science+Business Media, LLC 2017

The Symposium was held in Almería (Spain), 10-12 February 2016. The theme was 'Automation and ICT in Agriculture'. The event was organized by the Horticultural Engineering Group from the Horticultural Science Spanish Society (SECH) and by the University of Almería (Spain) (http://www2.ual.es/SNIH16/). The Spanish Society of Agricultural Engineering also contributed. Some of the latest advances in applied ICT in Agriculture from Spain and several foreign countries were presented. Papers were from different institutions related to these technologies: such as universities, research centres and enterprises.

A selection of several papers from this event is presented in this special issue of Precision Agriculture. The varied subjects give an idea of the great possibilities for advances in this technological and multi-disciplinary field. The paper topics include: use of cloud-based systems for data management, software application for meteorological calculation through mobile devices, an advanced system for selective spraying in greenhouses, application of cloud computing in lysimetry, use of a web application for grape management, risk management system for prediction of meteorological disasters in greenhouses.

A. Ruiz-Canales

aruizcanales@gmail.com

M. Ferrández-Villena

m.ferrandez@umh.es

1 Department of Engineering, Miguel Hernández University in Elche, Ctra. Orihuela-Beniel, km 3.2, 03312 Orihuela, Spain 